\title{
Assignment of Eubacterium sp. VPI 12708 and related strains with high bile acid $7 \alpha-$ dehydroxylating activity to Clostridium scindens and proposal of Clostridium hylemonae sp. nov., isolated from human faeces
}

\author{
Maki Kitahara, ${ }^{1}$ Fusae Takamine, ${ }^{2}$ Teisuke Imamura ${ }^{2}$ \\ and Yoshimi Benno ${ }^{1}$
}

Author for correspondence: Maki Kitahara. Tel: +8148 4679562. Fax: +81484624619.
e-mail: kitahara@jcm.riken.go.jp

1 Japan Collection of Microorganisms, RIKEN, Wako, Saitama 351-0198, Japan

2 Laboratory of Microbiology, School of Health Sciences, Faculty of Medicine, University of the Ryukyus, Okinawa 903-0215, Japan

\begin{abstract}
Unknown Eubacterium-like organisms VPI 12708 and five strains (Y-1113, I-10, M-18, TH-82 and 36S) had high bile acid $7 \alpha$-dehydroxylating activity; the unknown Clostridium-like organisms $\mathrm{TN}-271^{\mathrm{T}}$ and $\mathrm{TN}-272$ also had the same activity. Analysis of their $16 \mathrm{~S}$ rDNA sequences demonstrated that all strains belong to cluster XIVa of the genus Clostridium (Collins et al., 1994). Strain VPI 12708 and five other strains (Y-1113, I-10, M-18, TH-82 and 36S) formed a single cluster and strains $\mathrm{TN}-271^{\top}$ and $\mathrm{TN}-272$ formed another single cluster.

Clostridium scindens JCM $6567^{\top}$ was the most closely related species for two clusters in the phylogenetic tree. Values for DNA-DNA similarities among C. scindens JCM 6567', strain VPI 12708 and the other five strains were greater than $\mathbf{7 0} \%$, showing that these micro-organisms were a single species. Therefore, we identified strain VPI 12708 and the five other strains as C. scindens. In addition, DNA-DNA similarities among C. scindens JCM 6567', strain $\mathrm{TN}^{\mathrm{N}}-271^{\top}$ and strain $\mathrm{N}-272$ revealed that strains $\mathrm{TN}-271^{\top}$ and $\mathrm{TN}-272$ were distinct from C. scindens JCM $6567^{\top}$. On the basis of phylogenetic analysis and DNA-DNA similarity data, it was concluded that strains $\mathrm{TN}^{-271^{\top}}$ and $\mathrm{TN}-272$ are members of a new species of the genus Clostridium, for which the name Clostridium hylemonae is proposed. The type strain is strain $\mathrm{TN}^{\mathrm{2} 21^{\mathrm{T}}} \mathrm{(}=\mathrm{JCM}$ 10539').
\end{abstract}

Keywords: bile acid, $7 \alpha$-dehydroxylation, Clostridium scindens, Eubacterium sp. VPI 12708, Clostridium hylemonae

\section{INTRODUCTION}

Members of the genera Clostridium and Eubacterium are the predominant intestinal species exhibiting bile acid $7 \alpha$-dehydroxylating activity (Archer et al., 1982; Ferrari et al., 1977; Hayakawa \& Hattori, 1970; Hirano et al., 1981; Stellwag \& Hylemon,

\footnotetext{
The GenBank/EMBL/DDBJ accession numbers for the $16 \mathrm{~S}$ rDNA sequences reported in this paper are as follows: $\mathrm{AB} 020883$ (Clostridium scindens JCM $6567^{\top}$ ), AB020727 (C. scindens VPI 12708), AB020728 (C. scindens Y-1113), AB020729 (C. scindens M-18), AB020730 (C. scindens I-10), AB020731 (C. scindens TH82), AB020806 (C. scindens 36S), AB023972 (Clostridium hylemonae TN-271 ${ }^{\top}$ ) and $\mathrm{AB} 023973$ (C. hylemonae TN-272).
}

1979; Takamine \& Imamura, 1995). The presence of this activity in the intestinal microflora results in $7 \alpha$ dehydroxylation of cholic acid and chenodeoxycholic acid, yielding deoxycholic acid and lithocholic acid, respectively. Secondary bile acids have long been implicated in colorectal cancer as co-carcinogens (Batta et al., 1998; Cheah \& Bernstein, 1990; Hill, 1975; Mastromarino et al., 1976; Reddy, 1981; Reddy et al., 1977), indicating that bile acid $7 \alpha$-dehydroxylation is an important physiological reaction in the intestinal ecosystem.

Strain VPI 12708, an isolate from human faeces, was reported to exhibit bile acid $7 \alpha$-dehydroxylating ac- 
tivity and was identified as a member of the genus Eubacterium (White et al., 1980). After the characterization, many studies (Baron et al., 1991; Coleman et al., 1987; Doerner et al., 1997; Franklund et al., 1993; Mallonee \& Hylemon, 1996; Mallonee et al., $1990,1992)$ on strain VPI 12708 , especially on the bai (bile acid inducible) operon, have been reported. However, detailed studies concerning taxonomic research on strain VPI 12708 have not appeared. Takamine \& Imamura (1995) isolated and characterized some strains of bile acid $7 \alpha$-dehydroxylating bacteria and concluded that a few strains were members of the genus Eubacterium. Doerner et al. (1997) assessed bile acid $7 \alpha$-dehydroxylating bacteria for the presence of a bai-like gene by Southern hybridization. They found three types of bile acid $7 \alpha$-dehydroxylating bacteria: one type possessed all of the bai operon; one possessed none of the operon; and another possessed only some parts of the operon.

We consider that the taxonomic positions of strain VPI 12708 and other isolates from faeces of healthy humans should be clarified to determine which species are responsible for the bile acid $7 \alpha$-dehydroxylation reaction. The purpose of this study was to examine the taxonomic positions of strain VPI 12708 and other bile acid $7 \alpha$-dehydroxylating bacteria by means of $16 \mathrm{~S}$ rDNA sequencing and DNA-DNA similarity experiments.

\section{METHODS}

Bacterial strains and cultivation. Several bacterial strains with known bile acid $7 \alpha$-dehydroxylating activity were used in this study (Table 1). Strain VPI 12708 was originally isolated by $\mathrm{R}$. Hammann from the faeces of a colon-cancer patient. The media and techniques used were as described previously (White et al., 1980). The other strains (Y-1113, I10, M-18, TH-82, 36S, TN-271 ${ }^{\mathrm{T}}$ and TN-272) were isolated by $\mathrm{F}$. Takamine from the faeces of healthy humans, using previously described procedures (Doerner et al., 1997).

All of the bacterial strains were cultured on Eggerth-Gagnon (EG; Eiken) blood agar plates with $5 \%$ horse blood, GAM agar plates (Nissui) and egg-yolk agar plates for $2 \mathrm{~d}$ at $37^{\circ} \mathrm{C}$ in anaerobic jar boxes (Hirayama) filled with $100 \% \mathrm{CO}_{2}$. Egg-yolk agar plates contained the following: $20 \mathrm{~g}$ peptone, $2.5 \mathrm{~g} \mathrm{Na}_{2} \mathrm{PO}_{4}, 0.5 \mathrm{~g} \mathrm{~K}_{2} \mathrm{HPO}_{4}, 1 \mathrm{~g} \mathrm{NaCl}, 0.05 \mathrm{~g} \mathrm{MgSO}_{4}, 1 \mathrm{~g}$ glucose and $12.5 \mathrm{~g}$ agar in $500 \mathrm{ml}$ distilled water $(\mathrm{pH} 7 \cdot 6)$ and

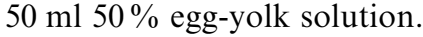

Physiological and biochemical tests. The basal medium for physiological and biochemical tests was PYF medium. The PYF medium was composed of $1000 \mathrm{ml}$ containing the following: $10 \mathrm{~g}$ trypticase (BBL; Becton Dickinson), $10 \mathrm{~g}$ yeast extract (Difco), $40 \mathrm{ml}$ Fildes' solution, $40 \mathrm{ml}$ salts solution and $0.5 \mathrm{~g} \mathrm{~L}$-cysteine. $\mathrm{HCl} . \mathrm{H}_{2} \mathrm{O}$; the $\mathrm{pH}$ was adjusted to 7.6. The salts solution contained $0 \cdot 2 \mathrm{~g} \mathrm{CaCl}_{2}, 0 \cdot 2 \mathrm{~g}$ $\mathrm{MgSO}_{4}, 1 \mathrm{~g} \mathrm{~K}_{2} \mathrm{HPO}_{4}, 1 \mathrm{~g} \mathrm{KH}_{2} \mathrm{PO}_{4}, 10 \mathrm{~g} \mathrm{NaHCO}_{3}, 2 \mathrm{~g} \mathrm{NaCl}$ and $1000 \mathrm{ml}$ distilled water. The Fildes' solution contained $150 \mathrm{ml}$ physiological saline, $6 \mathrm{ml}$ concentrated $\mathrm{HCl}, 50 \mathrm{ml}$ horse blood and $1 \mathrm{~g}$ pepsin $(1: 10000$; Difco); the $\mathrm{pH}$ was adjusted to $7 \cdot 6$ after digestion.

$\mathrm{H}_{2} \mathrm{~S}$ production, indole production, nitrate reduction, motility, aesculin hydrolysis, starch hydrolysis and gelatin liquefaction were detected by using the methods of Holdman et al. (1977).

Acid production from 30 sugars was determined by using PYF medium containing $0.5 \%(\mathrm{w} / \mathrm{v})$ sugar, excluding amygdalin and aesculin $(0.25 \%)$. The $\mathrm{pH}$ was measured directly in the culture tubes by using a combination electrode (an automatic, multipoint $\mathrm{pH}$-measuring system; Lifetech). The final $\mathrm{pH}$ was determined after incubation for $7 \mathrm{~d}$.

The metabolic end products were analysed by means of GLC (GC-14A; Shimadzu) using a $2 \cdot 1 \mathrm{~m}$ glass column (i.d. $2.8 \mathrm{~mm}$, FAL-M $25 \%$, Chrommosorb W, AW-DMCS $\mathrm{H}_{2} \mathrm{PO}_{4}, 80 / 100$ mesh). The short fatty acids were analysed by means of acidified ether-extraction.

The enzymic activity tests were performed using API ZYM (API bioMérieux) according to the instructions of the manufacturer.

16S rDNA analysis. Fragments (approx. 1500 bases) of the $16 \mathrm{~S}$ rDNA genes of strains used in this study were amplified by PCR with primers 5'-dAGAGTTTGATCCTGGCTCAG-3' (designated primer 27F) and 5'-dGGTTACCTTGTTACGACTT-3' (designated primer 1492R), using PCR Thermal Cycler MP (Takara Shuzo). The PCR products were purified using a GENE Mate PCR pure SPIN purification kit (Intermountain Scientific Corporation) and were sequenced using an AutoCycle sequencing kit (Pharmacia Biotech) and an ALF express DNA sequencer (Pharmacia Biotech). The new sequences were compared with the sequences of reference organisms from the GenBank database. Phylogenetic analysis was performed with the software CLUSTAL w (Thompson et al., 1994) and a phylogenetic tree was constructed according to the neighbourjoining method (Saitou \& Nei, 1987). The topology of the tree was evaluated by bootstrap analysis using the CLUSTAL W program (Thompson et al., 1994).

Nucleotide sequence accession numbers. The $16 \mathrm{~S}$ rDNA sequences of strain VPI 12708 and five strains have been deposited in the DDBJ database. The following 16S rRNA/ rDNA sequences were used for the phylogenetic analysis: Clostridium aerotolerans DSM 5434 ${ }^{\mathrm{T}}$ (X76163), Clostridium aminophilum VPI 14602 (L04165), Clostridium aminovalericum DSM $1283^{\mathrm{T}}$ (X73436), Clostridium celerecrescens DSM 5628 ${ }^{\mathrm{T}}$ (X71848), Clostridium clostridiiforme ATCC 25537 ${ }^{\mathrm{T}}$ (M59089), Clostridium coccoides DSM 2088 (M59090), Clostridium nexile DSM 1787 ${ }^{\mathrm{T}}$ (X73443), Clostridium oroticum ATCC 13619 ${ }^{\mathrm{T}}$ (M59109), Clostridium polysaccharolyticum DSM $1801^{\mathrm{T}}$ (X71858), Clostridium populeti ATCC $35295^{\mathrm{T}}$ (X71853), Clostridium sphenoides DSM 632 ${ }^{\mathrm{T}}$ (X73449), Clostridium symbiosum ATCC $14940^{\mathrm{T}}$ (M59112), Clostridium xylanolyticum ATCC 49623 (X71855), Coprococcus eutactus ATCC 27759 (D14148), Eubacterium cellulosolvens ATCC 43171 ${ }^{\mathrm{T}}$ (L34613), Eubacterium formicigenerans ATCC 27755 ${ }^{\mathrm{T}}$ (L34619), Eubacterium limosum KIST 612 (U67159), Roseburia cecicola ATCC $33874^{\mathrm{T}}$ (L14676), Ruminococcus hansenii ATCC $27752^{\mathrm{T}}$ (D14155), Ruminococcus productus ATCC 27340 (L76595) and Ruminococcus torques ATCC $27756^{\mathrm{T}}$ (L76604).

DNA base composition. DNAs were extracted from the cells harvested from EGF broth after growth for $12 \mathrm{~h}$ at $37^{\circ} \mathrm{C}$ and purified by the methods of Saito \& Miura (1963). DNA base compositions were determined using HPLC (Tamaoka \& Komagata, 1984) after enzyme digestion of DNA with deoxyribonucleosides. An equimolar mixture of four deoxy- 
Table 1. Strains used in this study

\begin{tabular}{|c|c|c|c|c|c|c|c|c|}
\hline \multirow[t]{2}{*}{ Strain* } & \multirow[t]{2}{*}{ Source } & \multirow[t]{2}{*}{ Reference } & \multicolumn{6}{|c|}{ Presence of bai genes $\dagger$} \\
\hline & & & baiB & baiE & baiA2 & baiG & baiH & bail \\
\hline $\begin{array}{l}\text { Clostridium scindens } \\
\text { JCM } 6567^{\mathrm{T}}\end{array}$ & Faeces of a healthy human adult & Morris et al. (1985) & + & + & + & + & + & + \\
\hline VPI 12708 (= JCM 10418) & Faeces of a colon-cancer patient & White et al. (1980) & + & + & + & + & + & + \\
\hline Y-1113 (= JCM 10419) & Faeces of a healthy human adult & $\begin{array}{l}\text { Takamine \& } \\
\text { Imamura (1995) }\end{array}$ & + & + & + & + & + & + \\
\hline M-18 (= JCM 10420) & Faeces of a healthy human adult & $\begin{array}{l}\text { Takamine \& } \\
\text { Imamura (1995) }\end{array}$ & NT & + & NT & NT & NT & NT \\
\hline $\mathrm{I}-10(=\mathrm{JCM} 10421)$ & Faeces of a healthy human adult & Doerner et al. (1997) & NT & + & NT & NT & NT & NT \\
\hline TH82 (= JCM 10422) & Faeces of a healthy human adult & Doerner et al. (1997) & + & + & + & + & + & + \\
\hline 36S (= JCM 10423) & Faeces of a healthy human adult & $\begin{array}{l}\text { Takamine \& } \\
\text { Imamura (1995) }\end{array}$ & + & + & + & + & + & + \\
\hline $\mathrm{TN}-271^{\mathrm{T}}\left(=\mathrm{JCM} 10539^{\mathrm{T}}\right)$ & Faeces of a healthy human adult & Doerner et al. (1997) & - & - & + & + & + & + \\
\hline TN-272 (= JCM 10540) & Faeces of a healthy human adult & None & - & - & + & + & + & + \\
\hline
\end{tabular}

* JCM, Japan Collection of Microorganisms; VPI, Virginia Polytechnic Institute; superscript T indicates that the strain is the type strain.

$\dagger$ According to Doerner et al. (1997); NT, not tested.

ribonucleotides in the GC kit (Yamasa Shoyu) was used as the quantitative standard.

DNA-DNA similarity. Levels of DNA-DNA similarity were determined by the method of Ezaki et al. (1989), using photobiotin and microplates.

\section{RESULTS}

\section{Biological characterization}

The spores of Clostridium scindens JCM $6567^{\mathrm{T}}$ were very difficult to demonstrate microsopically but were observed in strains from egg-yolk agar plates. Spore formation was not observed in strain VPI 12708 or in the other five strains (Y-1113, I-10, M-18, TH-82 and $36 \mathrm{~S})$, even from egg-yolk agar plates. The colony- and cell morphologies of strain VPI 12708 and the five strains were very similar to those of $C$. scindens JCM $6567^{\mathrm{T}}$.

In strains $\mathrm{TN}-271^{\mathrm{T}}$ and $\mathrm{TN}-272$, spore formation was observed on EG agar plates. The colony- and cell morphologies of strains $\mathrm{TN}-271^{\mathrm{T}}$ and $\mathrm{TN}-272$ were very similar to those of C. scindens JCM $6567^{\mathrm{T}}$ (Fig. 1).

\section{Physiological and biochemical properties}

The characteristics of the $C$. scindens and Clostridium hylemonae strains are summarized in Table 2. Strain VPI 12708 and the other five strains produced acid from fructose, glucose and ribose but not from adonitol, amygdalin, dulcitol, erythritol, aesculin, glycerol, glycogen, inositol, inulin, mannitol, melezitose, melibiose, rhamnose, salicin, sorbitol, sorbose,

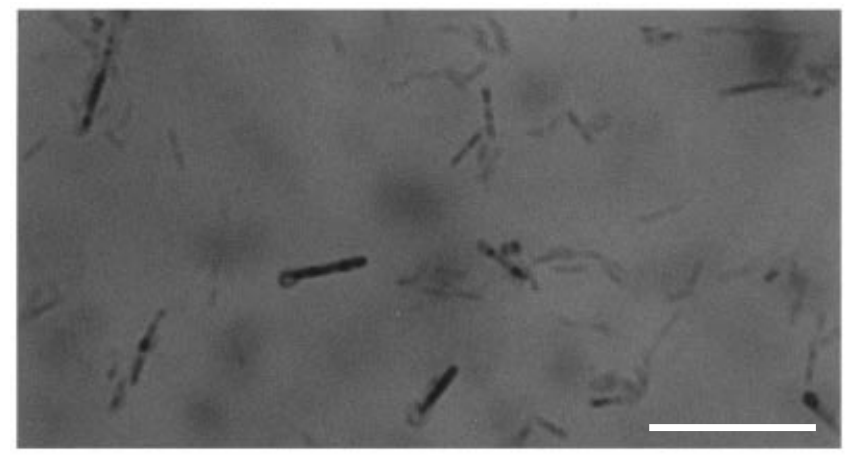

Fig. 1. Light micrograph of strain $\mathrm{TN}-271^{\top}$ showing terminal spores. Cells were cultured on GAM agar. Bar, $10 \mu \mathrm{m}$.

starch or trehalose. With regard to other sugars, each strain showed different sugar-fermentation patterns. With regard to biochemical properties, strain VPI 12708 and the other five strains showed gas formation, did not produce indole, did not reduce nitrate and did not liquefy gelatin. Only strain I-10 hydrolysed aesculin and starch. Strains Y-1113, M18 and 36S produced $\mathrm{H}_{2} \mathrm{~S}$.

Strains $\mathrm{TN}-271^{\mathrm{T}}$ and $\mathrm{TN}-272$ produced acid from galactose, glucose, raffinose and sucrose, but not from adonitol, amygdalin, cellobiose, dulcitol, erythritol, aesculin, glycerol, glycogen, inositol, inulin, lactose, mannitol, mannose, melezitose, melibiose, rhamnose, salicin, sorbitol, sorbose, starch or trehalose. For arabinose, fructose, maltose, ribose and xylose, strains 
Table 2. Characteristics of Clostridium scindens and Clostridium hylemonae

All strains of $C$. scindens and C. hylemonae produced acid from glucose.

\begin{tabular}{|c|c|c|c|c|c|c|c|c|c|}
\hline \multirow[t]{2}{*}{ Characteristic } & \multicolumn{7}{|c|}{ C. scindens } & \multicolumn{2}{|c|}{ C. hylemonae } \\
\hline & $\mathrm{JCM} 6567^{\mathrm{T}}$ & I-10 & Y-1113 & M18 & VPI 12708 & $36 S$ & TH82 & $\mathrm{TN}-271^{\mathrm{T}}$ & TN-272 \\
\hline Spore formation & + & - & - & - & - & - & - & + & + \\
\hline $\mathrm{H}_{2} \mathrm{~S}$ production & - & - & + & + & - & + & - & + & + \\
\hline Aesculin hydrolysis & - & + & - & - & - & - & - & - & - \\
\hline Starch hydrolysis & - & + & - & - & - & - & - & - & - \\
\hline \multicolumn{10}{|c|}{ Acid production from:* } \\
\hline Arabinose & - & - & + & + & + & + & + & + & - \\
\hline Xylose & - & - & + & + & + & + & + & + & - \\
\hline Ribose & + & + & + & + & + & + & + & + & - \\
\hline Mannose & + & + & - & - & - & - & + & - & - \\
\hline Fructose & + & + & + & + & + & + & + & + & - \\
\hline Galactose & + & + & + & - & + & + & + & + & + \\
\hline Sucrose & - & - & + & + & - & + & + & + & + \\
\hline Maltose & - & - & - & - & - & - & + & + & - \\
\hline Cellobiose & - & + & - & - & - & - & + & - & - \\
\hline Lactose & + & + & - & - & + & - & + & - & - \\
\hline Raffinose & - & - & - & - & - & - & + & + & + \\
\hline
\end{tabular}

* The fermentation tests were determined as positive $(+)$ when the $\mathrm{pH}$ of the medium was acidified more than $1 \cdot 0 \mathrm{pH}$ unit below that of the control without carbohydrates.

Table 3. Enzymic activities of $C$. hymenonae and C. scindens

Enzymic tests were performed with an API 20S system according to the instructions of the manufacturer. The quantities of hydrolysed substrate were as follows: + , $>20 \mathrm{nmol} ;(+), 1-20 \mathrm{nmol} ;-,<10 \mathrm{nmol}$. 1, Alkaline phosphatase; 2 , naphthol-AS-BI-phosphohydrolase; $3, \alpha$ galactosidase; $4, \beta$-galactosidase; $5, \alpha$-glucosidase. All of the strains shown gave the same results for the following enzyme activities (each result is given in parenthesis): esterase $(+)$, esterase lipase $(+)$, lipase $(-)$, leucine arylamidase $(-)$, valine arylamidase $(-)$, cystine arylamidase $(-)$, trypsin $(-)$, chymotrypsin $(-)$, phosphatase $(+), \beta$-glucuronidase $(-)$, $\beta$-glucosidase $(-), N$-acetyl- $\beta$-glucosamidase $(-), \alpha$ mannosidase $(-)$ and $\alpha$-fucosidase $(-)$.

\begin{tabular}{|lccccc|}
\hline Strain & $\mathbf{1}$ & $\mathbf{2}$ & $\mathbf{3}$ & $\mathbf{4}$ & $\mathbf{5}$ \\
\hline C. scindens JCM $6567^{\mathrm{T}}$ & - & + & - & + & - \\
C. scindens VPI 12708 & - & + & - & + & - \\
C. scindens I-10 & - & + & - & + & - \\
C. scindens Y-1113 & $(+)$ & + & - & - & - \\
C. scindens M18 & - & - & - & - & - \\
C. scindens 36S & - & - & - & - & - \\
C. scindens TH82 & - & - & - & - & - \\
C. hylemonae TN-271 & $(+)$ & + & $(+)$ & - & + \\
C. hylemonae TN-272 & $(+)$ & + & $(+)$ & - & + \\
\hline
\end{tabular}

$\mathrm{TN}-271^{\mathrm{T}}$ and $\mathrm{TN}-272$ showed different sugar-fermentation patterns. With regard to biochemical properties, strains $\mathrm{TN}-271^{\mathrm{T}}$ and $\mathrm{TN}-272$ did not produce indole, did not reduce nitrate, did not liquefy gelatin and did not hydrolyse aesculin or starch. Strains $\mathrm{TN}-271^{\mathrm{T}}$ and TN-272 showed gas formation and $\mathrm{H}_{2} \mathrm{~S}$ production.

\section{API ZYM analysis}

The enzymic activities of the $C$. scindens and $C$. hylemonae strains are shown in Table 3. Strains VPI 12708 and I-10 had the same enzyme-activity pattern as $C$. scindens JCM $6567^{\mathrm{T}}$, but strains Y-1113, M18, $36 \mathrm{~S}$ and TH82 had different patterms of enzyme activity relative to $C$. scindens $\mathrm{JCM} 6567^{\mathrm{T}}$. Strains TN$271^{\mathrm{T}}$ and TN-272 gave positive reactions on $\alpha$ galactosidase and $\alpha$-glucosidase, while all strains of $C$. scindens gave negative reactions.

\section{$16 S$ rDNA sequence analysis}

The 16S rDNA sequence of each strain was determined for approximately 1500 bases. It was clear that $C$. scindens JCM $6567^{\mathrm{T}}$ was positioned in cluster XIVa of the genus Clostridium (Collins et al., 1994). Strains VPI 12708, Y-1113, I-10, M-18, TH-82 and 36S formed a single cluster and C. scindens $\mathrm{JCM} 6567^{\mathrm{T}}$ was the most closely related species in the phylogenetic tree. The level of sequence similarity between $C$. scindens JCM $6567^{\mathrm{T}}$ and strain VPI 12708 was $99 \cdot 0 \%$.

Strains $\mathrm{TN}-271^{\mathrm{T}}$ and $\mathrm{TN}-272$ formed a single cluster and $C$. scindens $\mathrm{JCM} 6567^{\mathrm{T}}$ was the most closely related species in the phylogenetic tree, but the level of sequence similarity between C. scindens JCM $6567^{\mathrm{T}}$ and strain TN $-271^{\mathrm{T}}$ was only $91 \cdot 3 \%$. The phylogenetic 


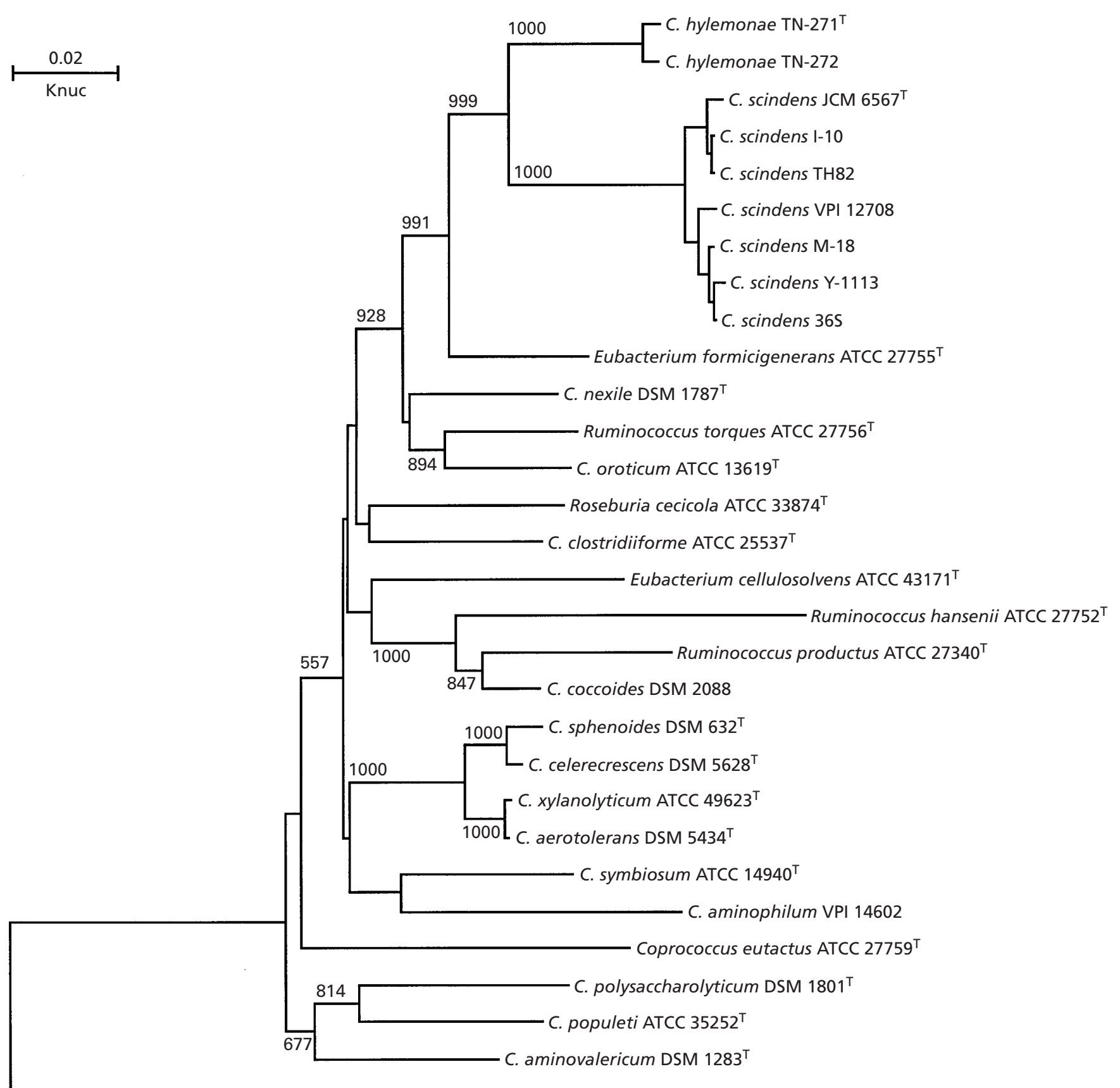

Eubacterium limosum KIST 612

Fig. 2. Phylogenetic relationships within Clostridium cluster XIVa and closely related species. The tree was created by using the neighbour-joining method and $K_{\text {nuc }}$ values. The numbers on the tree indicate bootstrap values greater than $50 \%$. Bar, $0.02 K_{\text {nuc }}$.

tree of clostridial cluster XIVa created with the representative strains is shown in Fig. 2.

\section{DNA base composition and DNA-DNA similarity}

DNA base compositions and levels of DNA-DNA similarity are shown in Table 4. C. scindens JCM $6567^{\mathrm{T}}$, strains VPI 12708 and the other five strains $(\mathrm{Y}-$ 1113, I-10, M-18, TH-82 and 36S) had G + C contents in the range $46 \cdot 0-47 \cdot 2 \mathrm{~mol} \%$. The reassociation of
DNA among C. scindens JCM $6567^{\mathrm{T}}$, strains VPI 12708, Y-1113, I-10, M-18, TH-82 and 36S was greater than $70 \%$. These findings clearly revealed that $C$. scindens JCM $6567^{\mathrm{T}}$, VPI 2708 and the other five strains were related genetically and that they formed a single species, as $C$. scindens.

Strains $\mathrm{TN}-271^{\mathrm{T}}$ and $\mathrm{TN}-272$ had the same $\mathrm{G}+\mathrm{C}$ content $(48.6 \mathrm{~mol} \%)$. The reassociation of DNA between strains $\mathrm{TN}-271^{\mathrm{T}}$ and $\mathrm{TN}-272$ was greater than 
Table 4. DNA base composition and levels of DNA-DNA similarity among C. scindens and C. hylemonae strains

\begin{tabular}{|c|c|c|c|c|c|c|c|c|c|c|}
\hline \multirow[t]{2}{*}{ Strain } & \multirow{2}{*}{$\begin{array}{l}\mathbf{G}+\mathbf{C} \\
\text { content } \\
(\mathrm{mol} \%)\end{array}$} & \multicolumn{9}{|c|}{ DNA-DNA reassociation (\%) with: } \\
\hline & & $\begin{array}{l}\mathrm{JCM} \\
6567^{\mathrm{T}}\end{array}$ & $\begin{array}{l}\text { VPI } \\
12708\end{array}$ & $36 \mathrm{~S}$ & Y-1113 & TH82 & $\mathrm{I}-10$ & M18 & TN-271 ${ }^{\mathrm{T}}$ & TN-272 \\
\hline \multicolumn{11}{|l|}{ C. scindens } \\
\hline $\mathrm{JCM} 6567^{\mathrm{T}}$ & $46 \cdot 5$ & 100 & 85 & 78 & 88 & 96 & 100 & 84 & 8 & 5 \\
\hline VPI 12708 & $47 \cdot 1$ & 95 & 100 & 97 & 101 & 88 & 94 & 112 & 11 & 7 \\
\hline $36 \mathrm{~S}$ & $46 \cdot 9$ & 84 & 96 & 100 & 98 & 75 & 82 & 109 & 8 & 5 \\
\hline Y-1113 & $47 \cdot 1$ & 89 & 100 & 100 & 100 & 79 & 89 & 108 & 10 & 6 \\
\hline TH82 & $46 \cdot 0$ & 95 & 83 & 75 & 79 & 100 & 102 & 97 & 7 & 4 \\
\hline $\mathrm{I}-10$ & $47 \cdot 2$ & 88 & 77 & 70 & 72 & 91 & 100 & 88 & 5 & 3 \\
\hline M18 & $47 \cdot 1$ & 78 & 91 & 91 & 93 & 70 & 70 & 100 & 5 & 3 \\
\hline \multicolumn{11}{|l|}{ C. hylemonae } \\
\hline $\mathrm{TN}-271^{\mathrm{T}}$ & $48 \cdot 6$ & 15 & 19 & 14 & 17 & 13 & 14 & 11 & 100 & 98 \\
\hline TN-272 & $48 \cdot 6$ & 20 & 22 & 16 & 19 & 15 & 18 & 12 & 103 & 100 \\
\hline
\end{tabular}

$98 \%$, while that between strain $\mathrm{TN}-271^{\mathrm{T}}$ and strains of C. scindens was less than $19 \%$. It clearly revealed that strains $\mathrm{TN}-271^{\mathrm{T}}$ and $\mathrm{TN}-272$ were distinct from $C$. scindens.

\section{DISCUSSION}

Many studies (Archer et al., 1982; Ferrari et al., 1977; Hayakawa \& Hattori, 1970; Hirano et al., 1981; Stellwag \& Hylemon, 1979; Takamine \& Imamura, 1995; White et al., 1980) on faecal bacteria having $7 \alpha$-dehydroxylating activity have been reported. In these reports, the multistep bile acid $7 \alpha-$ dehydroxylation pathway was studied in detail only for strain VPI 12708 (Baron et al., 1991; Coleman et al., 1987;Doerner et al., 1997; Franklund et al., 1993; Mallonee \& Hylemon, 1996; Mallonee et al., 1990, 1992). However, strain VPI 12708 was identified as a member of the genus Eubacterium; the detailed taxonomic position has not been reported. As in the case of strain VPI 12708 , other bile acid $7 \alpha$-dehydroxylating bacteria (strains Y-1113, I-10, M-18, TH-82, 36S, TN$271^{\mathrm{T}}$ and $\mathrm{TN}-272$ ) that were isolated and characterized (Doerner et al., 1997; Takamine \& Imamura, 1995) have been identified only as members of the genera Eubacterium and Clostridium and have not been identified at species level. The precise taxonomic positions of bile acid $7 \alpha$-dehydroxylating bacteria remain to be identified in the course of further studies.

In this study, we handled two groups on the basis of the hybridization results with each part of the bai operon. One is a group of strains (VPI 12708, Y-1113, TH82 and 36S) that possess all parts of the bai operon, while the other is a group of strains $\left(\mathrm{TN}-271^{\mathrm{T}}\right.$ and $\mathrm{TN}-$ 272) that possess four out of the six parts of the bai operon.

Strain VPI 12708 and the other five strains (Y-1113, I$10, \mathrm{M}-18, \mathrm{TH}-82$ and $36 \mathrm{~S}$ ) had different patterns of sugar fermentation and enzymic activity. However, the
16S rDNA sequence analysis showed that they were all closely related to $C$. scindens $\mathrm{JCM} 6567^{\mathrm{T}}$ on the phylogenetic tree presented in Fig. 2. The similarity level of the 16S rDNA sequences between strain VPI 12708 and $C$. scindens JCM $6567^{\mathrm{T}}(99 \cdot 0 \%)$ supported this phylogenetic relationship. The phylogenetic tree further demonstrated that the C. scindens type strain belongs to cluster XIVa of the genus Clostridium, although its $16 \mathrm{~S}$ rDNA sequence has not been deposited in the DDBJ database. As shown in Table 4, the DNA-DNA hybridization results demonstrated that strain VPI 12708 and the five strains had intergroup DNA similarity values of above $70.0 \%$, indicating that this group was composed of a single species that could be assigned to $C$. scindens.

Analysis of the 16S rDNA also showed that strains $\mathrm{TN}-271^{\mathrm{T}}$ and $\mathrm{TN}-272$ were closely related to $C$. scindens JCM $6567^{\mathrm{T}}$. However, as shown in Table 4, the levels of reassociation among strains $\mathrm{TN}-271^{\mathrm{T}}$, TN-272 and $C$. scindens JCM $6567^{\mathrm{T}}$ demonstrated that $\mathrm{TN}-271^{\mathrm{T}}$ and $\mathrm{TN}-272$ were clearly distinct from $C$. scindens JCM $6567^{\mathrm{T}}$ and belong to a new species of the genus Clostridium, for which we propose the name Clostridium hylemonae. The enzymic activities of $\alpha$ galactosidase and $\alpha$-glucosidase represent a useful method for phenotypically distinguishing between $C$. scindens and C. hylemonae, as shown in Table 3.

It is concluded that the taxonomic study of $16 \mathrm{~S} \mathrm{rDNA}$ was consistent with the bai gene hybridization pattern. Strains that possess all parts of the bai gene belong to C. scindens and strains that possess only some parts of this gene belong to a new species, i.e. C. hylemonae.

Thus, $C$. scindens and $C$. hylemonae are noted as bile acid $7 \alpha$-dehydroxylating bacteria of the human intestinal microflora. Furthermore, by the quantitative detection of $C$. scindens and C. hylemonae in the faeces of healthy humans and of colon-cancer patients, it may be possible to establish if bile acid $7 \alpha$-dehydroxylation 
of $C$. scindens and C. hylemonae is correlated with an increased risk of colon cancer.

\section{Description of Clostridium hylemonae sp. nov.}

Clostridium hylemonae (hai.le.mon'ae. N.L. gen. n. hylemonae of Hylemon, after the American microbiologist Phillip B. Hylemon, for his contributions to research on bile acid).

The description of the characteristics given below is based on the results of studies with the two strains TN$271^{\mathrm{T}}$ and TN-272. Cells are Gram-positive, sporeforming and non-motile. The straight or slightly curved, rod-shaped cells are $1 \cdot 0-5 \cdot 3 \times 0 \cdot 2-0.5 \mu \mathrm{m}$ in size and occur singly or in pairs. Colonies are $0.5-1.0 \mathrm{~mm}$ in diameter, disc-shaped and greyish in colour. The optimum temperature for growth is $37^{\circ} \mathrm{C}$ and the optimum $\mathrm{pH}$ is around 7.6. Obligately anaerobic. Two strains produce acid from galactose, glucose, raffinose and sucrose and have variable reactions with arabinose, fructose, maltose, ribose and xylose. None of the strains produce acid from adonitol, amygdalin, cellobiose, dulcitol, erythritol, aesculin, glycerol, glycogen, inositol, inulin, lactose, mannitol, mannose, melezitose, melibiose, rhamnose, salicin, sorbitol, sorbose, starch or trehalose. $\mathrm{H}_{2} \mathrm{~S}$ and gas are produced. Indole is not produced. Nitrate is not reduced. Aesculin and starch are not hydrolysed. Gelatin is not liquefied. Moderate amounts of acetic acid (as the endproduct) are produced in peptone/ yeast extract medium supplemented with glucose; minor amounts of propionic acid, iso-butyric acid, butyric acid and iso-valeric acid are also produced. The $\mathrm{G}+\mathrm{C}$ content of the DNA of strain TN $-271^{\mathrm{T}}$ is $48 \cdot 6 \mathrm{~mol} \%$. The type strain is strain TN-271 ${ }^{\mathrm{T}}$ and was isolated from the faeces of a healthy adult human. This strain has been deposited in the Japan Collection of Microorganisms (Saitama, Japan) as strain JCM $10539^{\mathrm{T}}$.

\section{ACKNOWLEDGEMENTS}

We thank Dr Y. Kosako, Dr Y. Cai, Dr M. Sakamoto and A. Kageyama for helpful discussions.

\section{REFERENCES}

Archer, R. H., Maddox, I. S. \& Chong, R. (1982). Transformation of cholic acid by Clostridium bifermentans. J Appl Bacteriol 52, 49-56.

Baron, S. T., Franklund, C. V. \& Hylemon, P. B. (1991). Cloning, sequencing and expression of the gene coding for bile acid $7 \alpha-$ hydroxysteroid dehydrogenase from Eubacterium sp. strain VPI 12708. J Bacteriol 173, 4558-4569.

Batta, A. K., Salen, G., Holubec, H., Brasitus, T. A., Alberts, D. \& Earnest, D. L. (1998). Enrichment of the more hydrophilic bile acid ursodeoxycholic acid in the fecal water-soluble fraction after feeding to rats with colon polyps. Cancer Res 58, 1684-1687.

Cheah, P. Y. \& Bernstein, H. (1990). Modification of DNA by bile acids: a possible factor on the etiology of colon cancer. Cancer Lett 49, 207-210.
Coleman, J. P., White, W. B. \& Hylemon, P. B. (1987). Molecular cloning of bile acid $7 \alpha$-dehydroxylase from Eubacterium sp. strain VPI 12708. J Bacteriol 169, 1516-1521.

Collins, M. D., Lawson, P. A., Willems, A., Cordoba, J., FernandezGarayzaval, J., Garcia, P., Cai, J., Hippe, H. \& Farrow, J. A. E. (1994). The phylogeny of the genus Clostridium: proposal of five new genera and eleven new species combinations. Int $J$ Syst Bacteriol 44, 812-826.

Doerner, K. C., Takamine, F., La Voie, C. P., Mallonee, D. H. \& Hylemon, P. B. (1997). Assessment of fecal bacteria with bile acid $7 \alpha$-dehydroxylating activity for the presence of bai-like genes. Appl Environ Microbiol 63, 1185-1188.

Ezaki, T., Hashimoto, Y. \& Yabuuchi, E. (1989). Fluorometric deoxyribonucleic acid-deoxyribonucleic acid hybridization in microdilution wells as an alternative to membrane filter hybridization in which radioisotopes are used to determine genetic relatedness among bacterial strains. Int J Syst Bacteriol 39, 224-229.

Ferrari, A., Scolastico, C. \& Beretta, L. (1977). On the mechanism of cholic acid $7 \alpha$-dehydroxylation by a Clostridium bifermentans cell-free extract. FEBS Lett 75, 166-168.

Franklund, C. V., Baron, R. F. \& Hylemon, P. B. (1993). Characterization of the baiH gene encoding a bile acid-inducible NADH: flavin oxidoreductase from Eubacterium sp. strain VPI 12708. J Bacteriol 175, 3002-3012.

Hayakawa, S. \& Hattori, T. (1970). $7 \alpha$-dehydroxylation of cholic acid by Clostridium bifermentans strain ATCC 9714 and Clostridium sordellii strain NCIB 6929. FEBS Lett 6, 131-133.

Hill, M. J. (1975). The role of colon anaerobes in the metabolism of bile acids and steroids, and its relation to colon cancer. Cancer 36, 2387-2400.

Hirano, S., Nakama, R., Tamaki, M., Matsuda, N. \& Oda, H. (1981). Isolation and characterization of thirteen intestinal microorganisms capable of $7 \alpha$-dehydroxylating bile acids. Appl Environ Microbiol 41, 737-745.

Holdeman, L. V., Cato, E. P. \& Moore, W. E. C. (1977). Anaerobe Laboratory Manual, 4th edn. Blacksburg, VA: Virginia Polytechnic Institute and State University.

Mallonee, D. H. \& Hylemon, P. B. (1996). Sequencing and expression of a gene encoding a bile acid transporter from Eubacterium sp. strain VPI 12708. J Bacteriol 178, 7053-7058.

Mallonee, D. H., White, W. B. \& Hylemon, P. B. (1990). Cloning and sequencing of a bile acid-inducible operon from Eubacterium sp. strain VPI 12708. J Bacteriol 172, 7011-7019.

Mallonee, D. H., Adams, J. L. \& Hylemon, P. B. (1992). The bile acid-inducible baiB gene from Eubacterium sp. strain VPI 12708 encodes a bile acid-coenzyme A ligase. J Bacteriol 174, 2065-2071.

Mastromarino, A., Reddy, B. S. \& Wynder, E. L. (1976). Metabolic epidemiology of colon cancer: enzymic activity of fecal flora. Am J Clin Nutr 29, 1455-1460.

Morris, G. N., Winter, J., Cato, E. P., Ritchie, A. E. \& Bokkenheuser, V. D. (1985). Clostridium scindens sp. nov., a human intestinal bacterium with desmolytic activity on corticoids. Int J Syst Bacteriol 35, 478-481.

Reddy, B. S. (1981). Dietary fat and its relationship to large bowel cancer. Cancer Res 41, 3700-3705.

Reddy, B. S., Watanabe, K., Weisburger, J. H. \& Wynder, E. L. (1977). Promoting effect of bile acids in colon carcinogenesis in germ-free and conventional F344 rats. Cancer Res 37, 3238-3242.

Saito, H. \& Miura, K. (1963). Preparation of transforming 
deoxyribonucleic acid by phenol treatment. Biochim Biophys Acta 72, 619-629.

Saitou, N. \& Nei, M. (1987). The neighbor-joining method: a new method for reconstructing phylogenetic trees. Mol Biol Evol 4, 406-425.

Stellwag, E. J. \& Hylemon, P. B. (1979). $7 \alpha$-Dehydroxylation of cholic acid and chenodeoxycholic acid by Clostridium leptum. $J$ Lipid Res 20, 325-333.

Takamine, F. \& Imamura, T. (1995). Isolation and characterization of bile acid $7 \alpha$-dehydroxylating bacteria from human feces. Microbiol Immunol 39, 11-18.
Tamaoka, J. \& Komagata, K. (1984). Determination of DNA base composition by reversed-phase high-performance liquid chromatography. FEMS Microbiol Lett 25, 125-128.

Thompson, J. D., Higgins, D. G. \& Gibson, T. J. (1994). CLUSTAL $\mathrm{W}$ : improving the sensitivity of progressive multiple sequence alignment through sequence weighting, position specific gap penalties and weight matrix choice. Nucleic Acids Res 22, 4673-4680.

White, B. A., Lipsky, R. L., Fricke, R. J. \& Hylemon, P. B. (1980). Bile acid induction specificity of $7 \alpha$-dehydroxylase activity in an intestinal Eubacterium species. Steroids 35, 103-109. 